\title{
USE QUESTIONNAIRE AND AHP TECHNIQUES TO DEVELOP SUBCONTRACT- OR SELECTION SYSTEM
}

\author{
Yan-Chyuan Shiau, Tsung-Pin Tsai, Wen-Chian Wang, Miao-Ling Huang \\ Associate Professor \\ Department of Construction Engineering \\ Chung Hua University \\ Email:ycshiau@ms22.hinet.net
}

\begin{abstract}
The construction scale is growing rapidly; therefore, to subcontract is a common style in Taiwan's construction industry. Selecting appropriate subcontractors is a key to assure the success of a construction project. With different environment, construction project usually invoke complex attributes. We need a good tool to help engineers to pick the best selections during various and complicate market. In this research, we use questionnaire to survey about 400 construction companies, which help us to obtain subcontractor selection factors and their weights. Subcontractors can fill available price for specific items from Quotation System, meanwhile, Appraisal System will integrate and calculate related data to determine total grades for all factories. Subcontractor Selection System can be used to compile all information about special area. Through the help of this system, Construction Company can use Internet to announce procurement, collect factory quotation and perform subcontractor selection. This can make the procurement process be fair, pick better partners, increase competition and create profit for company.
\end{abstract}

Keywords: AHP, Bid, Procurement, Quotation, Subcontractor Selection System.

\section{Introduction}

\section{A. Motive of the Study}

Comparing to other phases, such as planning, design, construction and so on, procurement consumes shorter time in the life cycle of a construction work. However, it is the key phase in which the cost of the project is determined. The selection of subcontractors often encounters problems, such as the selection of inappropriate subcontractors, difficulty in the management of subcontractors and out-ofcontrol of budget and quotation systems. Such problems might be caused by insufficient time for execution, complicated procedures or poor information channels. It is, therefore, important for construction companies to control the subcontractor selection operation and make sure to conduct it in a fair and objective manner.

\section{B. Objective of the Study}

The objective of the study is to analyze the aforementioned problems so as to:

A. Investigate the status quo of the subcontractor selection system in Taiwan;

B. Acquire the evaluation criteria and their weights by doing surveys and via AHP; and

C. Develop a Subcontractor Selection Management Aid System, including Basic Database, Budget Management Module and Subcontractor Selection Module.

\subsection{Scope of the Study}

The study is limited to the procurement and subcontractor selection operations of a construction company. Construction projects are used as the subjects of the study.

\subsection{Methodology and Process of the Study}

The method and process used in the study is shown in Fig. 1.

\section{Study of the Subcontractor Se- lection}

There are some problems in traditional subcontractor selection strategies:

C. Engineers always pick familiar subcontractors, therefore, cannot get the best bargain for company.

D. The purchasing message can 
only reach to limited subcontractors.

E. People can easily collude with subcontractor and commit cheat in close environment.

The subcontractor selection operation includes the determination of evaluation criteria and their weights. This is the most difficult operation to conduct effectively and fairly in the procurement phase.

The importance of subcontractor examination is described in [1]. The study finds that it is important to establish methodologies for the examination system and design a simple and easy-use examination sheet for the of subcontractor selection.

Huang, Chung-Fa divides the subcontractor management into six subtopics in [2] and makes comparison among them. The six subtopics are registration of new subcontractors, final selection of subcontractors, examination of subcontractors, payment, handle and remove of disputes, and scale economy of procurement. The selection of subcontractors is described as follows:

\subsection{Subcontractor Evaluation Form}

The subcontractor evaluation comprises "Evaluation Facets" and "Coordination of Facets and Evaluation Principles". In [2], the evaluation criteria and their weights are divided based on Work Quality, Progress Control, Cooperativeness, Safety Management, and Material Management. Some construction companies divide the evaluation criteria into 12 facets.

\subsection{Evaluation and Scoring}

Subjectivity is the factor unlikely to be eliminated in the evaluation of subcontractors. Different evaluators may evaluate one subcontractor differently. To prevent the objectivity of the evaluation from being affected by subject factors, it is required to establish a reliable scoring system for the evaluation.

\section{Evaluation Criteria and Weighing}

\subsection{Evaluation Criteria and Their Weights}

To acquire an objective analysis result, surveying is used to investigate the evaluation criteria and their weights. The perfect score is 100 . A fair, open and appropriate selection model is established by using the computer aided automatic calculation function in conjunction with arranged relative weights. It is used as a tool to select appropriate subcontractors in the awarding phase.

The flowchart of the evaluation criteria and their weights is shown in Fig. 2:

\subsection{Application of AHP}

\subsubsection{Introduction of AHP}

Analytic Hierarchy Process (AHP) is a decision analysis approach developed by Thomas L. Satty in 1971 [3]. As an easy-use and very practical tool based on a simple theory, AHP is capable to extract the comments of multiple experts and decision makers, and is mainly applicable to handling the problems arising in an uncertain environment in which multiple evaluation criteria exist. The AHP are used to systemize complicated problems and dissolve these factors into different levels from various directions. A comprehensive analysis is conducted via the process of quantification to assist decision makers in the selection of appropriate plans.

Many factors must be taken into consideration when operating the evaluation mechanism. The study uses AHP to establish a hierarchical structure for all affecting factors and acquires the weight of each factor by pair-wise comparison. The acquired weight distribution is more objective than setting the weight for individual factors.

\subsubsection{Steps of AHP Analysis}

The study uses AHP to conduct the decision analysis with reference to [4] and [5]. The steps of the analysis are described as follows:

The study uses AHP to conduct the decision analysis with reference to [4] and [5]. The steps of the analysis are described as follows:

1. Establishment of the Hierarchical Structure

After the final goal of establishing the hierarchical framework is achieved, a mutually independent hierarchical relationship is built by interviewing experts and doing surveys (secondary goal), and analyzing the elements that might affect the secondary goal. The elements of similar importance are collected on the same level in this step. (Fig. 3)

2. Weight between the Elements on Different Levels 
The calculation of the weight between the elements on different levels is completed though the following four steps:

\section{A. Establishment of Pair-wise Compar- ison Matrix:}

The element comparison is conducted in this step. The parent element of an element on a lower level is used as an evaluation criterion for the pair-wise comparison.

\section{B. Calculation of Priority Vector}

Divided each comparison value by the sum of the values in corresponding fields for the aggregation of the rows; namely, the sum of the percentage each comparison value occupies in its corresponding row.

$$
\sum_{i=1}^{n} \frac{\text { cell_value }_{i}}{\text { column_sum }_{i}}
$$

Formula (1) shows the sum of the percentage each comparison value occupies in its corresponding row. An $\mathrm{n} x$ 1 matrix is acquired in this step.

C. Calculation of the Maximum Eigenvalue $\lambda \max$ :

Multiply the entire matrix with the acquired priority vector to produce an $\mathrm{n}$ $\mathrm{x} 1$ matrix. Then divide this matrix by the priority vector to acquire unit vectors. Calculate sequentially the average of the unit vectors to acquire the maximum eigenvalue $\lambda$ max.

\section{Examination of Consistency:}

During the pair-wise comparison, discrepancies might occur between the results of the comparison and the decision. The consistence ratio of Satty's AHP is used to examine the consistency of the entire matrix.

\subsection{Arrangement of Evaluation criteria and Their Weights}

Surveys are done to 400 contractors and the consistency of the weight analyses is examined in the study. When the consistency is confirmed, the arrangement of the "Relative Weight Analysis of the Secondary Goal" and the "Relative Weight Analysis of the Evaluation Criteria" is conducted to acquire the overall relative weight. Table 1 shows the relative weight of the entire evaluation criteria.

\section{Development of the Subcontractors Se- lection System}

The system mainly comprises the maintenance of subcontractor's data, quotation module, subcontractor selection module, budget control module, report preparation and maintenance of relevant data.

\subsection{Maintenance of Subcontractor's Data}

The "Maintenance of subcontractor's data" provides the basic data of the subcontractor and the data of guarantors. The user is requested to input the data of the subcontractor (Fig. 4). The basic data includes the name, address, telephone number, fax number, name and ID number of the responsible person, and uniform number of the subcontractor. The scoring of each evaluation item is conducted based on the basic data.

\subsection{Quotation Module}

The $\ulcorner$ Quotation Module $\lrcorner$ provides the data of the subcontractor and the project, the settings of each quotation item and the quotation data. (Fig. 5). This system also provides an enquiry function for the user to enquire relevant data of the subcontractor.

When selecting the subcontractor and the project, the user may select the work to be quoted and input the selection in the field of Quotation Data (Fig. 6).

\subsection{Subcontractor Selection Module}

Price is usually the key criterion for the traditional subcontractors selection. However, this traditional price-oriented selection approach only emphasizes the price and neglects the quality, timeframe and other factors supposed to be considered during the procurement process [6]. In the period of recession, this approach may lead to an awarding price that is much lower than the average bidding price, bringing a higher risk of failure to the owner [7]. Since each construction company has different consideration for each project. People may want to adjust the weights for each evaluation factor to reflect the real need. This study, therefore, conducts the analyses simultaneously for each evaluation item. Different weights can be set depending on the demand of each project. 
The $\ulcorner$ Subcontractor Selection Module $\lrcorner$ provides the functions of project selection, setting of evaluation criteria, selection of subcontractors and awarding operation. The user is requested to choose a project and select the item to be evaluated from the options of the project. The system will arrange the subcontractors that have provided the quotation for the selected item. The user may then compare the quotation based on the data provided by the system (Fig. 7). During the awarding operation, the system will arrange the data to be compared and provide it to the user for the selection of subcontractors. When the awarding operation is completed, the system will calculate the awarding progress and aggregate the awarding amount.

\subsection{Budget Control Module}

The $\ulcorner$ Budget Control Module $\lrcorner$ provides the functions of project data selection and project quotation enquiry. When the awarding budget exceeds the planned budget, the system will give an alert to users (Fig. 8).

\subsection{Report Preparation}

All reports related to the procurement can be printed by using the $\ulcorner$ Report Preparation $\lrcorner$ function. The Progress Chart of Procurement can be printed by using the sub-function of the

$\ulcorner$ Report Preparation $\lrcorner$ (Fig. 9).

\subsection{Maintenance of Relevant Data}

This function provides the maintenance of unit data, owner's data, project data, basic database, resources data and selection data. The evaluation criteria and their weights are created by the system based on the calculation of Section 3.3. To provide scalability to meet the future demand, the system allows the user to input the data to be changed here.

\section{Conclusion}

The results of the study are described in the following two major points:

\subsection{Creation of Evaluation criteria and Their Weights}

The study analyzes the subcontractor selection operation and uses AHP to calculate the weight of each selected evaluation item. The evaluated items and their weights are then integrated into the aided system to select appropriate subcontractors under the consideration of the price. The project may be adjusted to meet actual demand. The evaluation criteria and their weights acquired in the study are shown in Table 1.

\subsection{Development of the Subcontractor Se- lection System}

The study discovers the shortcomings of the current procurement operations and proposes feasible management strategies. The developed aided system provides the functions of the maintenance of subcontractor's data, quotation module, subcontractor selection module, budget control module, report preparation and maintenance of relevant data, which are capable to provide the following services:

A. The system sets the tasks for selected project and create unit price analysis and resources management data for effective cost analysis and control.

B. The system can select appropriate subcontractors based on the result of the evaluation. A fair and open process is provided by the system for construction companies to select appropriate subcontractors objectively.

C. The system successfully combines the procurement operations with the budget control, and is capable to give an alert when the budget exceeds its range.

D. The system provides the progress control function for the procurement operations, so that the decision makers may investigate the progress.

E. The objectivity of the evaluation criteria and their weights is confirmed by the industry. Both the evaluation item and the weights can be adjusted depending on the demand of each project.

\section{Acknowledgement}

I woul $1 \cdot 1 \cdot 1$ Initial Compile for Appraisal Items
my appreclation to show Executive Y Questionnaire Design rt of the study.

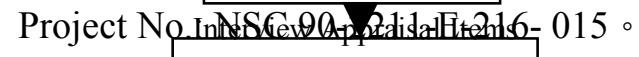

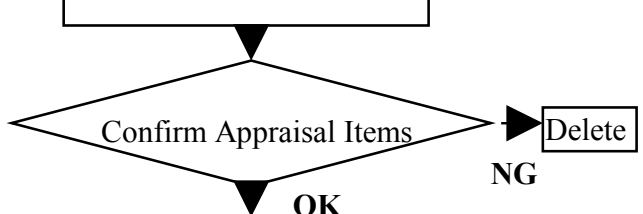

Questionnaire Design for Weight of Appraisal Items

Interview for Weight of Appraisal Items 
Fig. 1 Flowchart of this Research

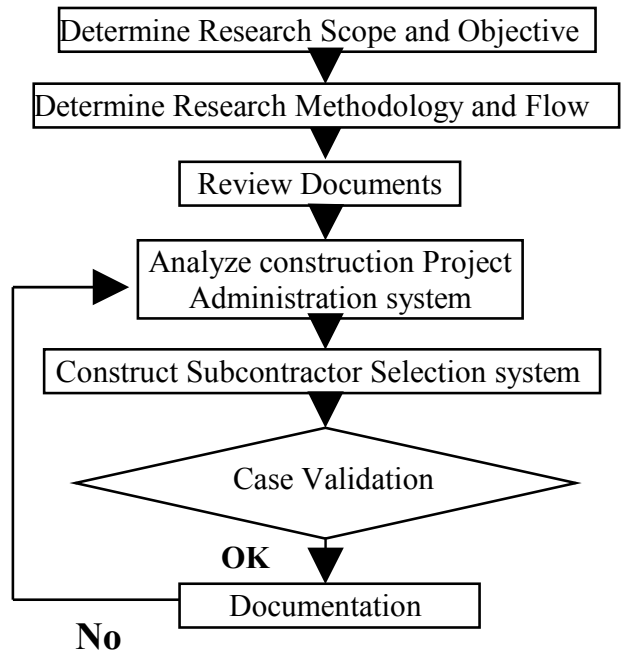

Fig. 2 Flowchart of Evaluation Criteria

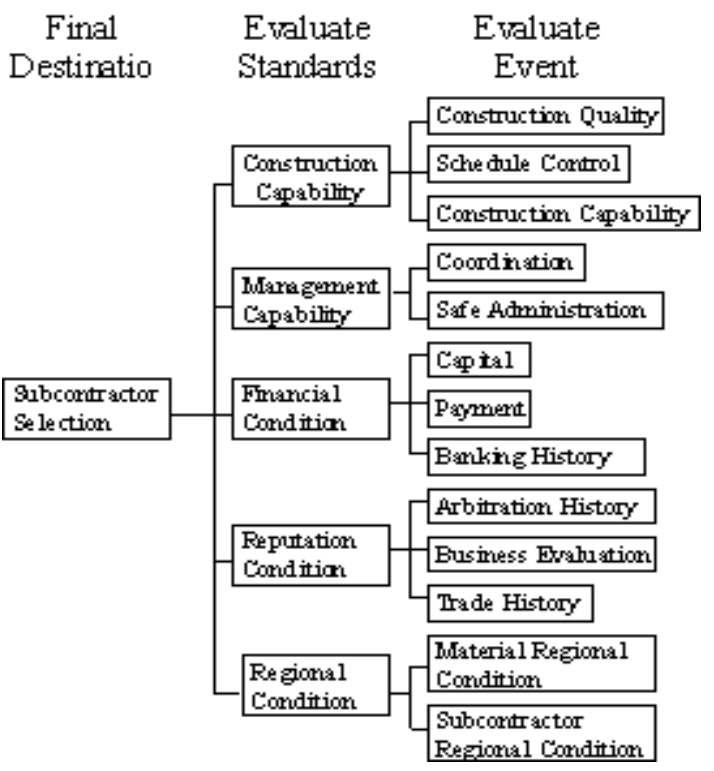

Fig. 3 Hierarchical Structure of the Factors for the Selection of Subcontractors

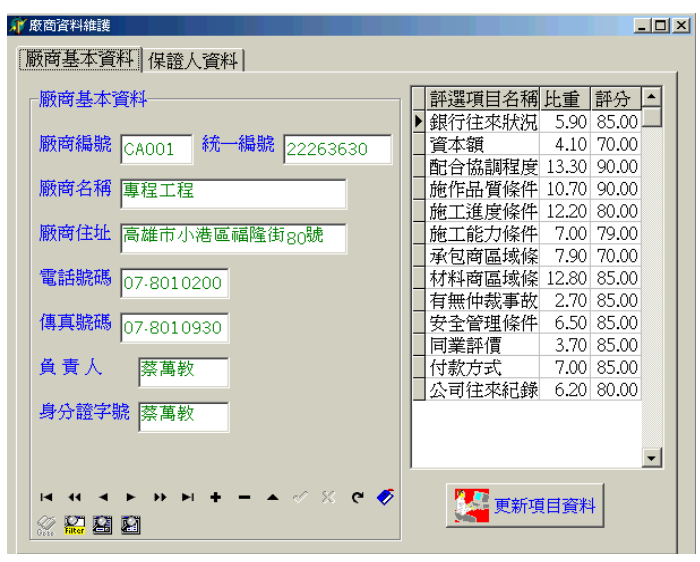

Fig. $4\ulcorner$ Data Maintenance $\lrcorner$ Dialog

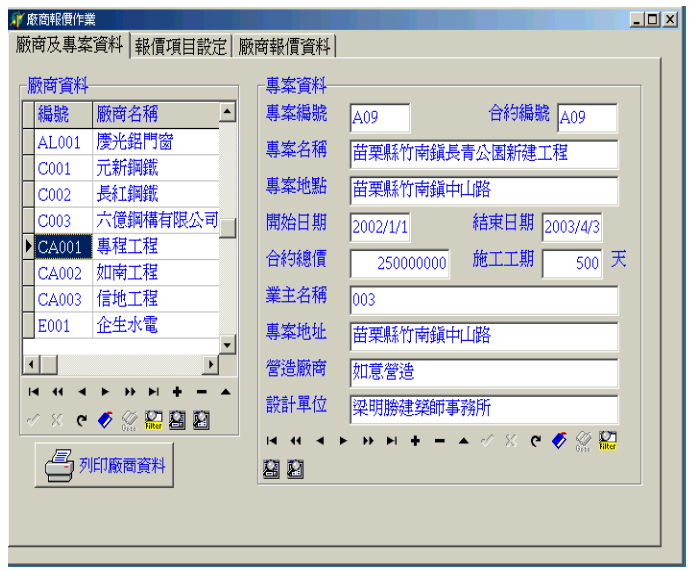

Fig. $5\ulcorner$ Quotation Module $\lrcorner$ Dialog

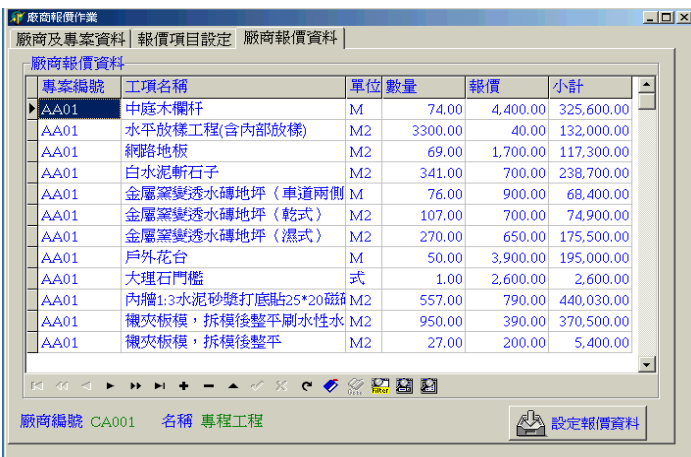

Fig. $6\ulcorner$ Quotation Data $\lrcorner$ Dialog

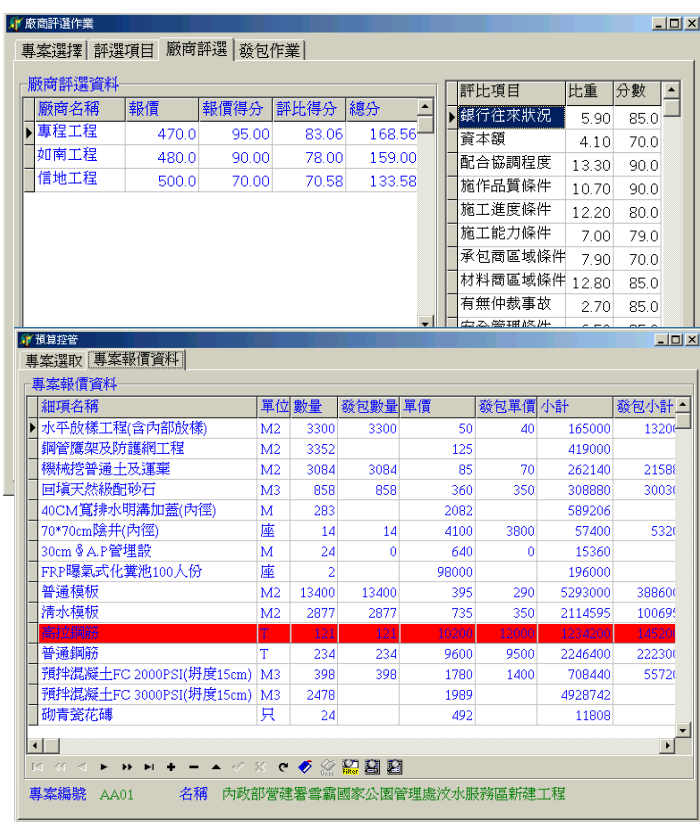


Fig. 8 Budget Control Screen

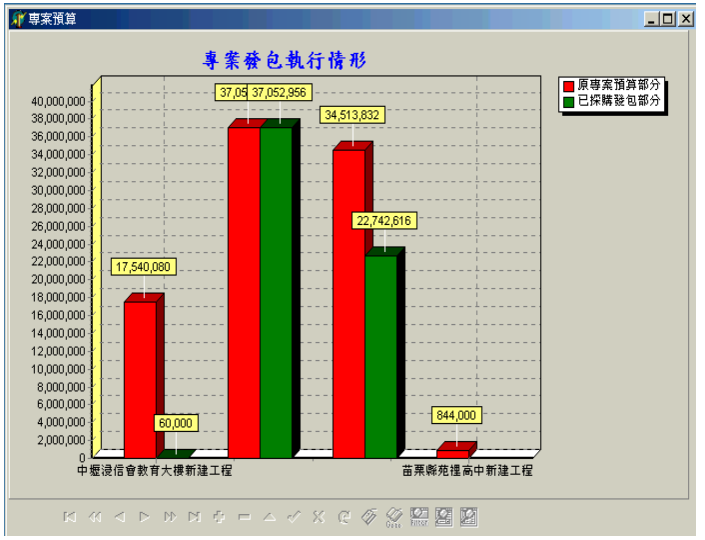

Fig. 9 Progress Chart of Procurement

Table 1. Relative Weight of the Evaluation Criteria

\begin{tabular}{|c|c|c|}
\hline \multicolumn{2}{|c|}{ Evaluate Standards } & Weight \\
\hline \multirow{3}{*}{$\begin{array}{l}\text { Construction } \\
\text { Capability }\end{array}$} & Construction Quality & 0.107 \\
\hline & Schedule Control & 0.122 \\
\hline & Construction Capability & 0.070 \\
\hline \multirow{2}{*}{$\begin{array}{l}\text { Management } \\
\text { Capability }\end{array}$} & Coordination & 0.133 \\
\hline & Safe Administration & 0.065 \\
\hline \multirow{3}{*}{$\begin{array}{l}\text { Financial } \\
\text { Condition }\end{array}$} & Capital & 0.041 \\
\hline & Payment & 0.070 \\
\hline & Banking History & 0.059 \\
\hline \multirow{3}{*}{$\begin{array}{l}\text { Reputation } \\
\text { Condition }\end{array}$} & Arbitration History & 0.027 \\
\hline & Business Evaluation & 0.037 \\
\hline & Trade History & 0.062 \\
\hline \multirow{2}{*}{$\begin{array}{l}\text { Regional } \\
\text { Condition }\end{array}$} & $\begin{array}{l}\text { Material Regional Condi- } \\
\text { tion }\end{array}$ & 0.128 \\
\hline & \begin{tabular}{|l|} 
Subcontractor Regional \\
Condition
\end{tabular} & 0.079 \\
\hline
\end{tabular}

\section{REFERENCES}

1. Ji-Zhong Zhang, "Research on Construc- tion Subcontract Management", Master Dissertation, Department of Science and Construction Engineering, National Taiwan Institute of Technology, Taipei, pp141 151, 1996.

2. Zhong-Fa Huang, "Research on Construction Subcontract Management of Tactic and Organization", Doctoral Dissertation, Department of Civil Engineering, National Central University, Tao-Yuan Taiwan, pp126 131, 2000.

3. Satty, T.L., "The Analytic Hierarchy Process", McGrawHill, New York, 1980.

4. Zhen-Yuan Deng And Guo-Xiong Zeng, "Application of Analytic Hierarchy Process (AHP) on Intension Characteristic And Analytic I", National Statistics Report, pp5 22, 1989.

5. Zhen-Yuan Deng And Guo-Xiong Zeng, "Application of Analytic Hierarchy Process (AHP) on Intension Characteristic And Analytic II", National Statistics Report, pp1 15, 1989.

6. Zohar Hersman and Ralph Ellis, "Multiparameter Bidding System-Innovation in Contract Administration" Journal of Construction Engineering and Management, ASCE, Vol.118, No1, pp142-150, 1992.

7. Gysbert J. R. Van Der Meulen and Arthur H.Money. “The Bidding Game,"Journal of Construction Engineering and Management, ASCE, Vol.110, No.2, pp153- 164, 1984. 